Int. J. Electrochem. Sci., 16 (2021) Article ID: 210730

International Journal of

ELECTROCHEMICAL

SCIENCE

$\underline{\text { www.electrochemsci.org }}$

\title{
The Mechanical Behavior and Microstructure of a Multilayer Nanostructured Ni-Co Alloy Fabricated by Electrodeposition
}

\author{
Xiaoxue Zhang, Xixun Shen*, Jiawen Chen \\ Shanghai Key Laboratory of Materials Protection and Advanced Materials in Electric Power, Shanghai \\ Engineering Research Center of Energy-Saving in Heat Exchange Systems, Shanghai University of \\ Electric Power, Shanghai 200090, PR China \\ "E-mail: shenxixun@shiep.edu.cn
}

doi: $10.20964 / 2021.07 .42$

Received: 14 March 2021 / Accepted: 3 May 2021 / Published: 31 May 2021

\begin{abstract}
A bulk multilayer nanostructured Ni-Co alloy with nano-grains (NG) layer with a thickness of $2.7 \mu \mathrm{m}$ and ultrafine grains (UFG) layer with a thickness of $0.9 \mu \mathrm{m}$ alternately grown is fabricated by an electrodeposition process. The analysis from X-ray diffractometer and transmission electron microscope reveal that the well-defined alternative layers consists of NG with a mean size of $23 \mathrm{~nm}$ with a random growth and UFG with a mean size of $90 \mathrm{~nm}$ along a (200) preferential growth. Tensile tests show that the multilayer nanostructured Ni-Co alloy exhibits an enhanced ductility with an elongation to failure of $14.2 \%$ and higher ultimate tensile strength of $1851 \mathrm{MPa}$ compared with the monolithic UFG and NG counterparts. The enhanced ductility for the multilayer nanostructured Ni-Co alloy is attributed to the improvement of work hardening ability brought by the action of the special microstructure involving the periodical distribution of UFG layer, the existence of interface and the alternation of crystal orientation between the layers in the dislocation activities and the effective adjustment to the local stress concentration brought by the periodic existence of the UFG layer in this layer structure. The higher strength sourced from the extra reinforcement provided by the hinder of interface to dislocation movement.
\end{abstract}

Keywords: Nanostructured Ni-Co alloy; Multilayer; Electrodeposition; Ductility; Strength

\section{$\underline{\text { FULL TEXT }}$}

(C) 2021 The Authors. Published by ESG (www.electrochemsci.org). This article is an open access article distributed under the terms and conditions of the Creative Commons Attribution license (http://creativecommons.org/licenses/by/4.0/). 